\title{
The EtnaPlumeLab (EPL) research cluster: advance the understanding of Mt. Etna plume, from source characterisation to downwind impacts.
}

\author{
Pasquale Sellitto ${ }^{1}$, Giuseppe Salerno ${ }^{2}$, Pierre Briole ${ }^{3 *}$ \\ 1 Laboratoire de Météorologie Dynamique (LMD), CNRS-UMR8539, Institut Pierre Simon Laplace, \\ École Normale Supérieure, École Polytechnique, Université Pierre et Marie Curie, Paris, France \\ psellitto@Imd.ens.fr \\ 2 Istituto Nazionale di Geofisica e Vulcanologia, Osservatorio Etneo, Catania, Italy \\ 3 Laboratoire de Géologie, CNRS-UMR8538, École Normale Supérieure, Paris, France
}

\begin{abstract}
In 2013, a multidisciplinary research cluster named EtnaPlumeLab (EPL) was established, gathering experts from volcanology and atmospheric science communities. Target of EPL is to advance the understanding of Mt. Etna's gas and aerosol emissions and the related processes, from source to its regional climatic impact in the Mediterranean area. Here, we present the cluster and its three interacting modules: EPL-RADIO (Radioactive Aerosols and other source parameters for better atmospheric Dispersion and Impact estimatiOns), SMED (Sulfur MEditerranean Dispersion) and Med-SuV (MEDiterranean SUpersite Volcanoes) Work Package 5. First results have provided pioneering highlights on the relevance of Mt. Etna's plume impact at the Mediterranean regional scale. These results underline that further efforts need to be made to get insight into a synoptic volcanogenic-atmospheric chemistry/climatic understanding of volcanic plumes impact.
\end{abstract}

\section{INTRODUCTION}

$\mathrm{M}$ ount Etna is a persistent source of gas and aerosols in the lower and upper Mediterranean troposphere. Its sulphur emission has been estimated to be about 10 times larger than anthropogenic emissions in the same area [Graf et al., 1997]. Recently, it has been shown that Mt. Etna has the potential to modulate the downwind aerosol properties, e.g. by the production of highlyreflective secondary sulphate aerosols from the conversion of sulphur dioxide emission
[Villani et al., 2006, Sellitto et al., 2016]. In its turn, this has revealed the potential to exert a significant direct regional climatic forcing, depending on the environmental conditions and the optical properties of the produced aerosols [Sellitto and Briole, 2015, Sellitto et al., 2016].

Though Mt. Etna is one of the most studied volcanoes in the world, e.g. [Bonaccorso et al., 2004], its atmospheric impact, from small-range air quality perturbation to far-range climatic forcing is not yet well understood, or even, its influence might be potentially underestimated. This is due

*This work has been partially supported by the European Union's Horizon 2020 research and innovation programme under grant agreement No 654182 (ENVRI+), the European Union's 7th Framework Program under the grant No 308665 (Med-SuV) and the INGV under the grant SMED. 
to the multidisciplinary ancestry of this argument, which require a synoptic investigation framework from inner-volcanology to atmospheric sciences and climatology. This integrated framework would allow to better characterise the volcanic degassing and to refine and tune the atmospheric chemistry/physics and climate sciences modelling, to better understand both tropospheric and stratospheric downwind impacts. Based on this undeniable objects, in 2013 a multidisciplinary research cluster named EtnaPlumeLab (EPL) was kicked-off. This cluster results from the combination of three different interacting projects. Here, we will detail the scopes, rationale and perspectives of EPL. The paper is structured as follows: Sect. II reports the general structure of EPL, in Sect. III the three different modules that constitute the EPL cluster are detailed and finally in Sect. IV conclusions and perspectives are given.

\section{A MULTIDISCIPLINARY AND} MULTISCALE MODULAR APPROACH FOR THE CHARACTERISATION OF VOLCANIC

\section{PLUMES}

The EPL research cluster aims at a better understanding of Mount Etna's gas and particulate emissions, their generation, evolution and impacts. The target area is the Mediterranean basin. The cluster arises from the interacting combination of three different modules/projects:

- EPL-RADIO (Radioactive Aerosols and other source parameters for better atmospheric Dispersion and Impact estimatiOns);

- SMED (Sulfur MEditerranean Dispersion);

- Med-SuV (MEDiterranean SUpersite Volcanoes) WP (work package) 5.

Figure 1 shows the spatial extent and the volcanic and atmospheric processes tackled by the three EPL modules, as well as their interactions. The EPL-RADIO project is specifically devoted to source characterisation, in terms of geochemistry and degassing processes, and the near-source plume characterisation. The SMED project investigates the dispersion of the $\mathrm{SO}_{2}$ emissions in the Central Mediterranean region, whereas the Med-SUV WP5 project, though its multipack volcanology scope, also promotes the study of the impact of Mt. Etna's emissions at a broader regional scale. The SMED and the Med-SuV WP5 projects superpose to a certain geographical extent. 


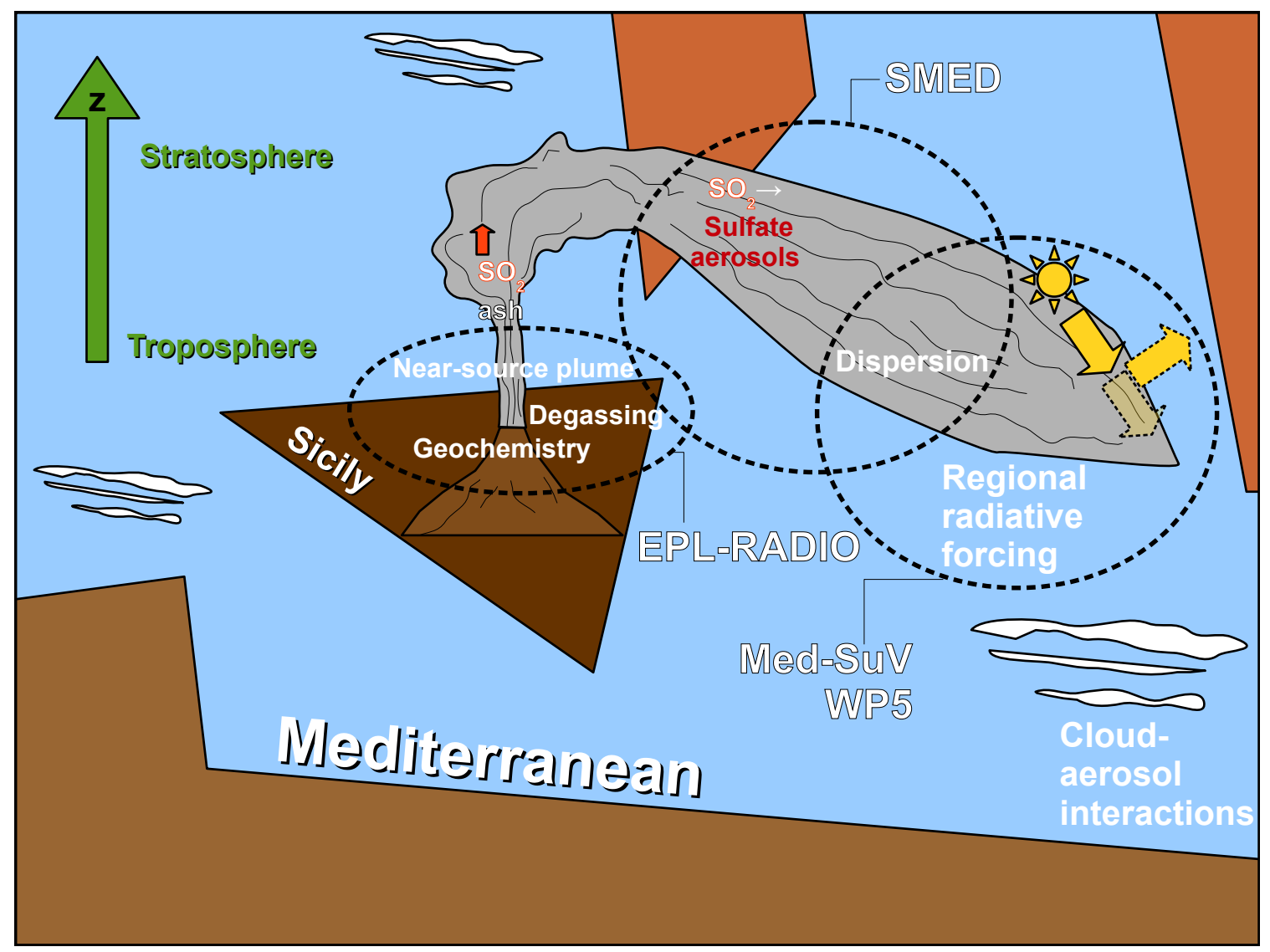

Figure 1: Spatial extents and interactions of the three modules establishing the EPL reserch cluster.

Figure 2 shows the structure of the EPL research cluster into the three modules. The modules are interacting and knowledge gathered from one module (at smaller spatial scale) is fed to the following module (at larger spatial scale). For instance, EPL-RADIO has the potential to provide input source parameters for the dispersion modelling tackled by SMED; on the other hand SMED has the potential to give plume's parameters such as to define optical downwind aerosols properties essential for the climatic impact estimation explored by Med-SuV WP5. The different scientific targets and the methods employed in each of the three modules (e.g., modelling and observations) are also indicated and color-coded. The timeframes of the modules are also shown. The broad split into (a) source - EPL-RADIO , (b) evolution - SMED, and (c) impact - Med-SuV WP5, of Mt. Etna emissions follows from Fig. 1. The EPL research cluster relies on high quality direct and remote ground- and satellitebased observations of volcanic plume, together with chemistry, transport and radiative transfer modelling. While for the SMED and Med$\mathrm{SuV}$ the employ of both observations and modelling is needed, EPL-RADIO is only based on ground- and satellite-based measurements for characterising the aerosol source (including gaseous precursors of secondary aerosols). The Med-SuV project ended in December 2015, but results are still available for further investigation. The SMED project runs from November 2015 to end 2016. The EPL-RADIO activities are foreseen until summer 2017. 


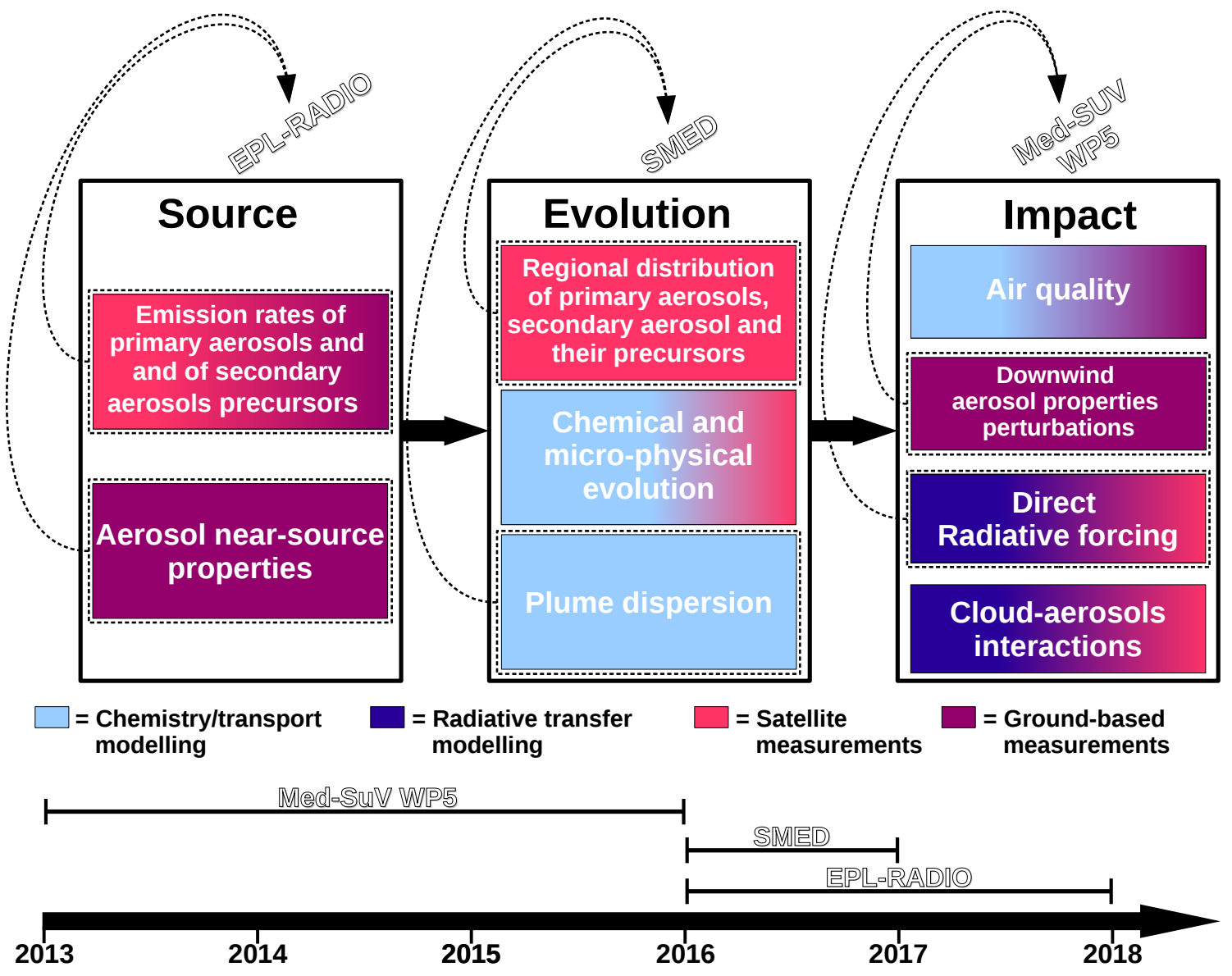

Figure 2: Breakdown of the EPL research cluster, with indication of scientific targets, methods and timeframes of the three individual modules of the cluster.

\section{THE DIFFERENT MODULES}

\section{III.1 EPL-RADIO}

The EPL-RADIO project aims at improving the characterisation of Mt. Etna as atmospheric aerosols source, gathering multi-domain (solid Earth and atmospheric sciences) information [Sellitto, 2016]. Object of EPL-Radio is to advance our knowledge on Mt. Etna's emissions, targeting emission processes, from inner degassing mechanisms to aerosol near-source characterisation.

This project brings together different and original information, such as observations of (a) radioactive disequilibria of radon daughters, (b) coupled direct/remote size-resolved aerosols distribution, (c) primary/secondary near-source sulfate aerosols partitioning. This volcanic aerosols decription allows a detailed size-resolved physicochemical characterisation of the emitted aerosols. The point (a) is more thoroughly discussed by Terray et al. (2016).

The volcanic aerosol source is characterised by determining the size-resolved aerosol emissions, with a cascade impactor and a Microtops-II optical spectrometers (see, e.g. [Mather et al., 2004]), and the primary fraction of the emitted sulfate aerosols (with respect to the secondary sulfate aerosols produced by in-plume conversion of $\mathrm{SO}_{2}$ emissions) by FTIR (Fourier Transform Infrared) spectroscopy [La Spina et al., 2010]. Complementary three-dimensional aerosols information is obtained with a scanning AMPLE Li- 
DAR (Aerosol Multi-wavelength Polarization Lidar Experiment - Light Detection And Ranging) system [Scollo et al., 2015]. These parameters are crucial to assess the size-dependent plume dispersion and downwind climatic impacts, and are then an input knowledge for the SMED and Med-SuV WP5 modules.

The EPL-RADIO project is linked to an extended transnational access at Mt. Etna's summit craters area, partially funded by the European Union's Horizon 2020 research and innovation programme (ENVRI+ TNA). Two dedicated campaigns have been scheduled in 2016 (C1: aerosol sampling at the summit craters, C2: distal observations in an area of about 30 $\mathrm{km}$ from the craters) and 2 in 2017 (C3 and C4). Highest priority is given to $\mathrm{C} 1$ and $\mathrm{C} 3$, i.e. the field experiments at the summit craters.

First, preliminary results of campaigns $\mathrm{C} 1$ and $\mathrm{C} 2$ have shown how near-source processes (in the first few $\mathrm{km}$ downwind the emitting craters) play a major role in determining the volcanic aerosol properties downwind, thus influencing the dispersion and impacts of the plume.

\section{III.2 SMED}

The SMED project [Salerno et al., 2016] aims at assessing: (a) the spatial distribution of the regional atmospheric dispersion of Mt. Etna's volcanic emissions, (b) the impact of moderate volcanic activity and long-lived passive degassing, and (c) lower to upper tropospheric sulphate aerosol formation processes and lifecycle, in the regional area of Central-Eastern sector of the Mediterranean basin.

While the project is mostly target to the Central-Eastern Mediterranean, where up to $80 \%$ of the Etnean plume disperses [Sellitto et al., 2017], the less downwindventilated Central-Southern Mediterranean region is also explored [Sellitto et al., 2016].

The study is pursued by a comprehensive set of remote ground- and satellite-based measurements, such as: (a) the INGV - Osservatorio Etneo FLAME (FLux Automatic MEasurements) ultraviolet scanning spectrom- eter network [Salerno et al., 2009] and FTIR [La Spina et al., 2010] measurements, (b) low Earth orbit (MODIS - MODerate resolution Imaging Spectroradiometer, IASI - Infrared Atmospheric Sounding Interferometer) and geostationary (SEVIRI - Spinning Enhanced Visible and InfraRed Imager) satellite sensors, (c) the AERONET (AErosol RObotic NETwork - http:/ /aeronet.gsfc.nasa.gov) stations in Nicolosi(Catania), Italy, and in the CentralEastern Mediterranean, (d) the ENEA superstation for climate observation in Lampedusa. The AERONET stations routinely measure column optical and microphysical properties of the aerosol layer, which are used to assess the downwind impact of Mt. Etna's sulphur emissions. Additionally, the Lampedusa station is equipped with complementary instrumentation, including a LiDAR which provides height resolved aerosol and clouds information. These data allow the characterization of aerosol layer and their precursors, which is fundamental for identifying downwind volcanic contribution. Ground and space observations are complemented with an atmospheric Lagrangian model (FLEXPART - FLEXible PARTicle dispersion model, https:/ /flexpart.eu/) for inspecting the transport and dispersion of volcanic plumes over the Mediterranean region.

First results have allowed the characterization of the Etnean plumes dispersion at the decadal timescale, thus quantifying the frequency of ventilation of different mediterranean sub-sectors and confirming the prevalence (about $80 \%$ frequency) of the dispersion of the plumes towards the eastern quadrant (i.e., towards Greece) [Sellitto et al., 2017].

\section{III.3 Med-SuV WP5}

The European Union's 7th Framework Program Med-SuV project aims at improving the assessment capacity of volcanic hazards in selected supersites (i.e., well instrumented sites) of Southern Italy. The main targets of this project are the optimisation and integration of existing and new observation/monitoring systems, the systematic study of volcanic pro- 
cesses and the enhancement of the coordination between the scientific and end-user communities.

Work package (WP) 5 of Med-SuV is devoted to improve the knowledge of processes occurring at Mt. Etna supersite. The primary aim of Med-SuV WP5 is the study of inner volcanology processes. Nevertheless, the degassing, transport and atmospheric impacts of Mt. Etna are also addressed. One specific target of Med-SuV WP5 is to extend the scopes of the Vamos Seguro (Volcanic Ash Monitoring and fOrecaSting between Sicilia and malta arEa and sharinG of the resUlts foR aviation safety) project (http://www.vamosseguro.eu/) and to study the downwind impacts of Mount Etna's ash and $\mathrm{SO}_{2}$ emissions in the central Mediterranean. In such a sense, Med-SuV WP5 extends geographically the scopes of SMED (see Fig. 1), allowing to investigate the regional impacts of volcanic emissions in the Central Mediterranean.

These interacting studies have shown, for the first time, that even relatively weak eruptions have the potential to modulate the optical and micro-physical properties of the aerosol layer at hundreds of $\mathrm{km}$ from Mt. Etna, thus exerting a significant, episodic radiative forcing [Sellitto et al., 2016], which is critically dependent from chemical/micro-physical processes in atmosphere [Sellitto and Briole, 2015]. The radiative impact is studied with both radiative transfer modelling and satellite observations of radiative fluxes. Longer-term analyses have shown that Mt. Etna's sulphur emissions can have a significant decadal impact on aerosol optical properties even in weakly ventilated subsectors, like observed at Lampedusa (southwestern quadrant) [Sellitto et al., 2017].

\section{Conclusion and Perspectives}

Emissions of volcanic gases and particles profoundly impact on terrestrial environment, atmospheric composition and climate, at various temporal and spatial scales. Early research results suggested that the regional impact of Mt. Etna in the Mediterranean might be poten- tially underestimated. A novel and vigorous multidisciplinary approach is then required to explore this subject. Hence, in 2013, the EPL multidisciplinary and multiscale research cluster has been established, aiming at a better characterisation of Mt. Etna's emissions, from source to downwind impacts.

First results have shown pioneering evidences of Mt. Etna's impacts in the Mediterranean, in terms of the modulation of the aerosol optical properties and of the potential direct radiative forcing at selected locations. The near-craters and near-source distal EPLRADIO campaigns, foreseen for the summers 2016 and 2017, will provide further insights into the degassing and emission processes, and near-source plume characterisation. This will allow to refine the regional dispersion modelling and help the interpretation of satellite data at the regional scale. On the other hand, the SMED activities will provide an overall picture of the dispersion and regional distribution of volcanic effluents in the Mediterranean, that will give better direct climatic forcing estimations.

Further important topics, not addressed at present by EPL are the modelling and observation of the chemical and micro-physical evolution of the plume, the role of volcanic aerosol in the formation, determination of optical properties and climatic forcing of low and high clouds and, at a smaller spatial scale, the impact of volcanic emissions on local and regional air quality (see Fig. 2). Further research is ongoing to include these aspects in the research cluster.

\section{ACKNOWLEDGEMENTS}

All participants of the EPL-RADIO, SMED and MedSuV WP5 projets are gratefully acknowledged, especially: T. Caltabiano, E. Carboni, S. Corradini, A. di Sarra, P.-J. Gauthier, A. La Spina, B. Legras, L. Merucci, G. Puglisi, S. Scollo, L. Terray. 


\section{REFERENCES}

[Bonaccorso et al., 2004] Bonaccorso, A. et al. (2004). Mt. Etna: Volcano Laboratory. American Geophysical Union publisher, Washington, DC, 143.

[Graf et al., 1997] Graf, H. F. et al. (1997). Volcanic sulfur emissions: Estimates of source strength and its contribution to the global sulfate distribution. J. Geophys. Res., 102(10), 10727-10738.

[La Spina et al., 2010] La Spina, A. et al. (2010). Unravelling the processes controlling gas emissions from the central and northeast craters of Mt. Etna. J. Volcanol. Geotherm. Res., 198(3-4), 368-376.

[Mather et al., 2004] Mather, T. et al. (2004). Characterization and evolution of tropospheric plumes from Lascar and Villarrica volcanoes, Chile. J. Geophys. Res., 109, D21303.

[Salerno et al., 2009] Salerno, G. et al. (2009). Three-years of SO2 flux measurements of Mt. Etna using an automated UV scanner array: comparison with conventional traverses and uncertainties in flux retrieval. J. Volcanol. Geotherm. Res., 183, 76-83.

[Salerno et al., 2016] Salerno, G. et al. (2016). SMED - Sulphur MEditerranean Dispersion. Geophys. Res. Abstr., 18, EGU20168131, 2016.

[Scollo et al., 2015] Scollo, S. et al. (2015). Lidar measurements carried out during the 28 February 2013 lava fountain event at Mt. Etna, in Italy. Geophys. Res. Abstr., 17, EGU2015-10137.
[Sellitto and Briole, 2015] Sellitto, P. and Briole, P. (2015). On the radiative forcing of volcanic plumes: modelling the impact of Mount Etna in the Mediterranean. Ann. Geophys., 58, doi:10.4401/ag-6879.

[Sellitto, 2016] Sellitto, P. (2016). The EPL-RADIO project co-funded by ENVRIplus, ENVRIplus Newsletter \#3, 2016 http://www.envriplus.eu/wpcontent/uploads/2015/08/EPL-radio.pdf.

[Sellitto et al., 2016] Sellitto, P. et al. (2016). Synergistic use of Lagrangian dispersion and radiative transfer modelling with satellite and surface remote sensing measurements for the investigation of volcanic plumes: the Mount Etna eruption of 2527 October 2013. Atmos. Chem. Phys., 16, 6841-6861.

[Sellitto et al., 2017] Sellitto, P. et al. (2017). The impact of Mount Etna sulfur emissions on the atmospheric composition and aerosol properties in the central Mediterranean: a statistical analysis over the period 2000-2013 based on observations and Lagrangian modelling Atmos. Environ.,148, 77-88.

[Terray et al., 2016] Terray, L. et al. (2016). Degassing dynamics at Mount Etna inferred from radioactive disequilibria $(210 \mathrm{~Pb}$ 210Bi-210Po) in the volcanic plume. Geophys. Res. Abstr., 18, EGU2016-10373-3.

[Villani et al., 2006] Villani, M. G. et al. (2006). Transport of volcanic aerosol in the troposphere: The case study of the 2002 Etna plume. J. Geophys. Res., 111, D21102. 